\title{
MONOCYTE TISSUE FACTOR EXPRESSION, CELL ACTIVATION, AND THROMBIN FORMATION DURING CARDIOPULMONARY BYPASS: A CLINICAL STUDY
}

Mats Ernofsson, BM, PhD ${ }^{b}$

Stefan Thelin, MD, $\mathrm{PhD}^{\mathrm{a}}$

Agneta Siegbahn, $\mathrm{MD}, \mathrm{PhD}^{\mathrm{b}}$
Objectives: Cardiopulmonary bypass is associated with extensive thrombin generation and cell activation. Our main hypothesis in this study was that the expression of tissue factor on circulating monocytes contributes to the formation of thrombin. Methods: Markers of activation of the coagulation cascade and cell activation were measured in 26 patients undergoing elective heart operations randomized to the use of heparin-coated (Duraflo II, $n=13)$ or standard cardiopulmonary bypass circuits $(n=13)$. Results: Thrombin generation, measured as the thrombin-antithrombin complex, increased considerably during cardiopulmonary bypass with peak levels 3 hours afterward and with remaining elevation 20 hours later. Despite increased monocyte and granulocyte activation and increased levels of monocyte chemotactic protein-1, which upregulates monocyte tissue factor expression in vitro, monocyte tissue factor expression was not increased at the end of cardiopulmonary bypass. Furthermore, at this time the monocytes were less sensitive to in vitro stimulation by endotoxin. These results might be explained by simultaneous enhanced levels of interleukin-10, which effectively downregulates monocyte tissue factor expression in vitro. Twenty hours after cardiopulmonary bypass was discontinued, the tissue factor expression on freshly isolated monocytes and on monocytes stimulated by endotoxin was significantly increased compared with preoperative levels. At this time increased activation markers of granulocytes, monocytes, and lymphocytes were also recorded. None of the measured parameters was found to be different between the groups. Conclusions: The tissue factor expression on circulating monocytes is upregulated the day after heart operations. The clinical relevance and the regulatory mechanism behind the enhanced expression, however, are not fully elucidated. (J Thorac Cardiovasc Surg 1997;113:576-84)
D uring heart operations with cardiopulmonary bypass (CPB), thrombin generation is extensive and therefore heparin is administered at high con-

From the Departments of Clinical Chemistry ${ }^{\mathrm{b}}$ and Thoracic and Cardiovascular Surgery, ${ }^{a}$ University Hospital, Uppsala, Sweden.

Supported by grants from the Selander Fund, the University Hospital, Uppsala, the Uppsala County Association Against Heart and Lung Diseases, and the Swedish Medical Research Council (project B96-13X-11568-01A)

Received for publication August 6, 1996; revisions requested Sept. 5, 1996; revisions received Sept. 30, 1996; accepted for publication Oct. 29, 1996.

Address for reprints: Agneta Siegbahn, MD, PhD, Department of Clinical Chemistry, University Hospital, S-751 85 Uppsala, Sweden.

Copyright (C) 1997 by Mosby-Year Book, Inc.

$0022-5223 / 97 \$ 5.00+0 \quad \mathbf{1 2 / 1 / 7 8 9 2 4}$ centrations. ${ }^{1,2}$ In addition, CPB induces strong activation of different leukocytes. ${ }^{3,4}$ It has been speculated that the contact of the blood with the extracorporeal circuit, via the intrinsic coagulation pathway, is the main contributor to the increased thrombin generation. ${ }^{5}$ Elevated levels of activated coagulation factor XII (factor XIIa) during CPB support this theory. ${ }^{6} \mathrm{It}$ is, however, doubtful that the contact activation is the main source of the thrombin generation. First, Boisclair and coworkers ${ }^{7}$ have published data that suggest that the main trigger of the coagulation is provided via the tissue factor (TF) pathway as a result of factor VIIa bonded to TF. The TF/factor VIIa complex then activates the coagulation cascade through the activation of factors IX and X. Second, levels of thrombin were formed in a patient with severe factor XII deficiency that were comparable to levels in patients with 
Table I. Clinical characteristics and intraoperative and postoperative data of the patient groups

\begin{tabular}{lcc}
\hline & Group HC & Group C \\
\hline Gender (No. of patients) & & \\
$\quad$ Male & 8 & 11 \\
Female & 5 & 2 \\
Age (yr) & $69 \pm 6.8$ & $72 \pm 6.5$ \\
Operation type (No. of patients) & & \\
AVR + CABG & 8 & 11 \\
AVR & 3 & 2 \\
MVR + CABG & 2 & 0 \\
CPB time (min) & $152 \pm 30$ & $139 \pm 29$ \\
Aortic crossclamping (min) & $92 \pm 17$ & $89 \pm 19$ \\
Time of ventilator support (hr) & $14.4 \pm 19.5$ & $9.9 \pm 4.7$ \\
Blood loss on day 1 (ml) & $934 \pm 347$ & $792 \pm 520$ \\
Retransfused drained blood (ml) & $752 \pm 395$ & $665 \pm 413$ \\
\hline
\end{tabular}

No significant differences existed between the two groups. The data are presented as mean plus or minus the standard deviation. $A V R$, aortic valve replacement; $C A B G$, coronary artery bypass grafting; $M V R$, mitral valve replacement.

normal factor XII undergoing cardiac operation. ${ }^{8}$ Thus factor XII activation is not always indispensable for thrombin generation during heart operations. Extracorporeal circuits coated with heparin are generally believed to be more biocompatible than uncoated surfaces, because they reduce contact activation of the coagulation cascade and have fewer cell-activating properties. ${ }^{9}$ However, most authors report no reduction in thrombin generation in patients operated on with use of this type of device whereas others have found evidence of some possible benefit of these surfaces on the coagulation cascade. $^{2,10-12}$

In this work, we focused on the circulating monocytes as a source of TF. Normally there is no TF or only trace amounts of TF in contact with the blood. Monocytes are, however, able to express TF on activation by different stimuli, including endotoxin, immune complexes, tumor necrosis factor, interleukin-1 $\beta$ (IL-1 $\beta)$, and monocyte chemotactic protein-1 (MCP-1). ${ }^{13,14}$ Moreover, the induction of TF is highly dependent on cellular interactions between different leukocytes and platelets. ${ }^{15,16}$ It has also been shown that the activation of the monocytes through the adhesion molecule CD11b increases TF expression. ${ }^{17}$ In contrast to these inducing agents, IL-4, IL-10, and IL-13 are cytokines with the potency to inhibit the generation of TF at the gene level. ${ }^{18}$

Recently, Kappelmayer and associates ${ }^{19}$ showed that simulated extracorporeal circulation induces the expression of TF on circulating monocytes. Our

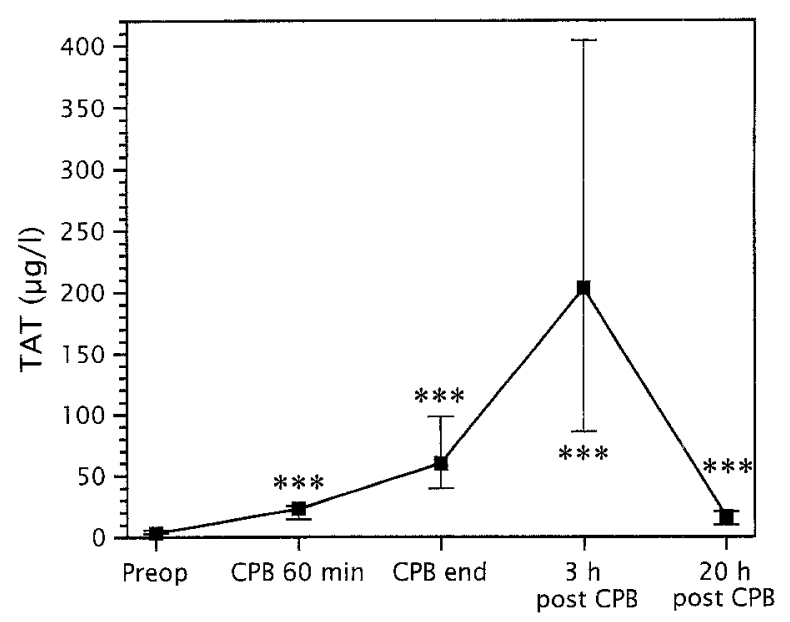

Fig. 1. The concentration of TAT levels before, during, and after CPB. TAT levels increased during CPB with maximum levels being reached 3 hours after the conclusion of CPB. On the first postoperative morning, the TAT levels had decreased but were still significantly elevated compared with preoperative values. Data are expressed as medians and $25 \%$ to $75 \%$ ranges. ${ }^{* *} p<0.001$ in comparison with preoperative levels.

main hypothesis was that monocyte $\mathrm{TF}$ is, at least partly, the cause of the enhanced thrombin generation during $\mathrm{CPB}$. Therefore we measured the TF expression on the surface of freshly isolated monocytes. To investigate whether the monocytes were primed during $\mathrm{CPB}$, we also stimulated the monocytes in vitro with endotoxin. The possible effect of cellular interactions between monocytes, lymphocytes, and granulocytes on the TF expression was also evaluated. To test the hypothesis that heparincoated surfaces have a beneficial effect on coagulation and cell activation, we randomly allocated the patients to operations with either heparin-coated (Bentley Duraflo II system) or conventional, uncoated surfaces.

\section{Patients and methods}

Patients. The study groups comprised 26 patients scheduled for cardiac procedures that were expected to be longer than standard procedures. The patients were randomized to receive CPB with use of either heparin-coated oxygenator, tubing, connectors, and blood cardioplegia sets (group HC) (Duraflo II, Baxter) or an uncoated but otherwise identical circuit (group C) (Univox, Baxter). In both groups the patients received standard heparin, that is, $300 \mathrm{IU} / \mathrm{kg}$ body weight, and CPB was started when the activated clotting time was longer than 480 seconds. Additional heparin doses were given if the activated 

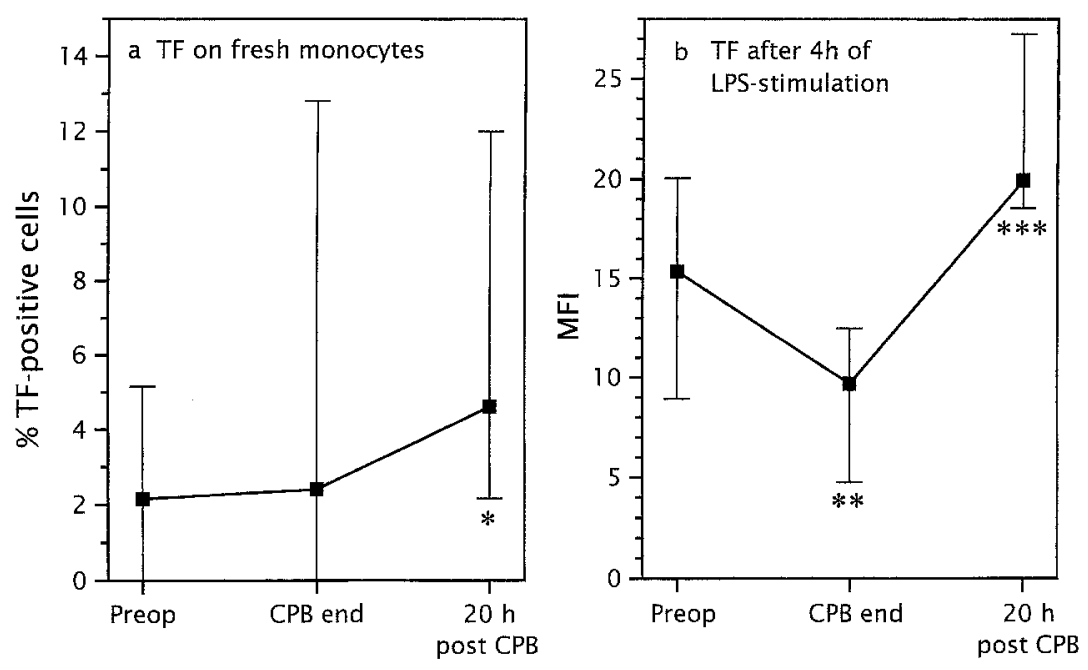

Fig. 2. TF levels before and after CPB (a) on freshly isolated monocytes and (b) after 4 hours of stimulation with $0.1 \mu \mathrm{g} / \mathrm{ml}$ of lipopolysaccharide (LPS). TF levels on fresh monocytes were elevated 20 hours after the end of CPB. At this time all patients had monocytes expressing TF. At the end of CPB, the monocytes expressed less TF after lipopolysaccharide stimulation compared with the preoperative levels. The cells were more sensitive to the stimulus the day after the operation. Data are presented as medians and $25 \%$ to $75 \%$ ranges. ${ }^{*} p=0.02 ;{ }^{* *} p=0.003 ;{ }^{* * *} p<0.001$ in comparison with preoperative levels.

clotting time fell to less than 480 seconds. After the patients were weaned from $\mathrm{CPB}$, protamine was given for heparin reversal. The study protocol was approved by the Ethical Committee of the Medical Faculty. Informed consent was obtained from all patients.

Anesthesia. Morphine and scopolamine were used for premedication and anesthesia was induced with thiopentone and fentanyl. Muscle relaxation was achieved with pancuronium. The lungs were ventilated with $50 \% \mathrm{~N}_{2} \mathrm{O}$ in oxygen until shortly before CPB was started, when nitrous oxide administration was discontinued. Ventilation after $\mathrm{CPB}$ was with oxygen in air. Fentanyl and isoflurane were used to maintain anesthesia.

CBP. The CPB technique was the same in both groups. A Stöckert heart-lung machine (Stöckert Instrumente, Munich, Germany) was used. After the aorta was crossclamped, an initial dose of cold blood cardioplegic solution $\left(10^{\circ}\right.$ to $\left.12^{\circ} \mathrm{C}\right)$ was administered in an antegrade fashion and antegrade or retrograde administration was repeated when needed. Moderate body hypothermia $\left(28^{\circ}\right.$ to $30^{\circ} \mathrm{C}$ ) was used and the blood flow was nonpulsatile starting at $2.2 \mathrm{~L} / \mathrm{min}$ per square meter of body surface area and then decreased by $25 \%$ at $30^{\circ} \mathrm{C}$. Patients were rewarmed to $36^{\circ} \mathrm{C}$ (rectal) before weaning from bypass. Drained blood was retransfused from the end of the operation until 16 hours after operation.

Blood samples and measurements. Arterial blood was sampled after induction of anesthesia, after 60 minutes of $\mathrm{CPB}$, at the end of $\mathrm{CPB}$, and at 3 hours and 20 hours after the discontinuation of CPB. Samples for activated clotting time were taken whenever indicated. Blood samples during CPB were drawn from the arterial line of the heartlung machine and at the other times from a catheter in the radial artery. After centrifugation, the plasma was immediately frozen and stored at $-70^{\circ} \mathrm{C}$ until analysis.

Plasma levels of thrombin-antithrombin complex (TAT) and cytokines were quantified by sandwich enzyme-linked immunosorbent assay techniques (Enzygnost TAT test, Behringwerke, Marburg, Germany, and Quantikine IL-10, soluble IL-2R $\alpha$, and MCP-1 tests, R \& D Systems, Abingdon, United Kingdom). The activated clotting time was assessed with the Hattersly technique with use of a Hemochron model 400 analyzer (International Technidyne, Edison, N.J.) and coagulation test tubes (celite diatomaceous earth activated, CA 510). Erythrocyte volume fraction and leukocyte count, including cell differentiation, were determined with an automatic cell counter (Coulter, Hialeah, Fla.). The results were not corrected for hemodilution.

Endotoxin determination. All chemicals used for the induction of tissue factor were checked with a sensitive chromogenic Limulus amebocyte lysate assay as previously described. ${ }^{14,20}$ Only chemicals negative to endotoxin $(<5 \mathrm{pg} / \mathrm{ml})$ were used for in vitro incubation of monocytes.

Preparation of leukocytes. For analysis of $\mathrm{CD} 11 \mathrm{~b}$ on monocytes and granulocytes and of human leukocyte antigen-DR on $\mathrm{CD}^{+} \mathrm{T}$ lymphocytes, leukocytes were isolated by the use of ammonium chloride lysis of erythrocytes, as originally described by Hamblin and colleagues ${ }^{21}$ and modified by us: arterial blood was sampled in heparin tubes (Terumo Venoject, Leuven, Belgium) after induction of anesthesia, at the end of CPB, and 20 hours after $\mathrm{CPB}$. The blood was mixed with equal amounts of $0.4 \%$ paraformaldehyde in a phosphate-buffered saline buffer and incubated at $37^{\circ} \mathrm{C}$ for 3 minutes. A 

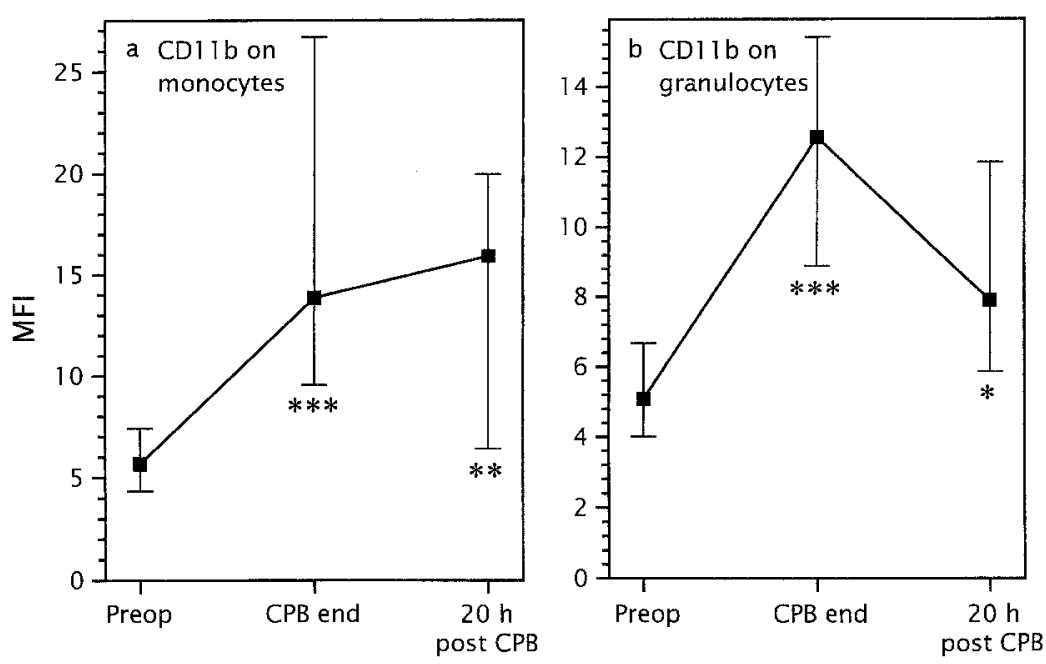

Fig. 3. Levels before and after CPB of the adhesion molecule CD11b on (a) monocytes and (b) granulocytes as measured by flow cytometry analysis. CD11b levels increased during CPB on both monocytes and granulocytes. In the monocytes, the levels remained unchanged 20 hours after $\mathrm{CPB}$ whereas CD11b levels decreased in the granulocytes. The data are shown as medians and $25 \%$ to $75 \%$ ranges. ${ }^{*} p=$ $0.04 ;{ }^{* *} p=0.002 ; * * * p<0.001$ in comparison with preoperative levels.

20 -fold excess of $0.83 \%$ ammonium chloride lysing buffer in $0.01 \mathrm{~mol} / \mathrm{L}$ Tris was added followed by 15 minutes of incubation at $37^{\circ} \mathrm{C}$. The cells were washed twice in phosphate-buffered saline solution and placed on ice.

Mononuclear cell separation and induction of TF expression. Arterial blood samples were taken into heparin tubes (Terumo Venoject) after induction of anesthesia, at the end of CPB, and 20 hours after discontinuation of CPB. For the analysis of TF, mononuclear cells were isolated by gradient centrifugation with the use of FicollPaque gradient. ${ }^{14}$ The cell suspension obtained by this procedure contained $20 \%$ to $35 \%$ monocytes, $60 \%$ to $80 \%$ lymphocytes, and $0 \%$ to $5 \%$ granulocytes before operation; $10 \%$ to $30 \%$ monocytes, $70 \%$ to $90 \%$ lymphocytes, and $0 \%$ to $10 \%$ granulocytes at the end of CPB; and $30 \%$ to $60 \%$ monocytes, $30 \%$ to $60 \%$ lymphocytes, and $0 \%$ to $10 \%$ granulocytes the morning after the operation. Cells for the analysis of TF on freshly isolated monocytes were immediately stained with antibodies and analyzed by flow cytometry.

To study whether the monocytes were primed in vivo, the cells were first stimulated in vitro $\left(37^{\circ} \mathrm{C}, 5 \% \mathrm{CO}_{2}\right)$ for 4 hours by $0.1 \mu \mathrm{g} / \mathrm{ml}$ of lipopolysaccharide (Sigma, St. Louis, Mo.) as previously described. ${ }^{14}$

Flow cytometry analysis. Analyses of cell surface structures were done in samples from 20 of the 26 patients $(10$ group $\mathrm{C}$ and 10 group $\mathrm{HC}$ ). The cells were stained as previously described ${ }^{14}$ with one or two of the following monoclonal antibodies: anti-tissue factor (TF9-9C3, Corvas, San Diego, Calif.), anti-CD14 ${ }^{\text {FITC }}$ (TÜK4, Dakopatts, Glostrup, Denmark), CD4 ${ }^{\mathrm{PE}}$ (MT310, Dakopatts), human leukocyte antigen-DR ${ }^{\text {FTC }}$ (CR3/43, Dakopatts), and CD $11 b^{P E}$ (Leu-15, Becton Dickinson, San Jose, Calif.). Irrelevant antibodies of appropriate immunoglobulin $G$ subclasses, concentrations, and fluorochrome (Dakopatts) were used as negative controls. The TF-stained cells were further stained with a fluorescein isothiocyanate-labeled $\mathrm{F}\left(\mathrm{ab}^{\prime}\right)_{2}$ fraction of a rabbit anti-mouse immunoglobulin (Dakopatts). The stained cells were fixed in $1 \%$ paraformaldehyde buffer and kept on ice until analysis was done with an EPICS Profile II flow cytometer (Coulter). Gating of the cells was done with side and forward light scatter properties in combination with anti-CD14 (monocytes) or anti-CD4 ( $\mathrm{T}$ helper/inducer lymphocytes) stained cells. The mean fluorescence intensity units (MFI) and the percentage of positive cells were determined for each sample.

Statistical analysis. The Statistica for Windows program (StatSoft, Tulsa, Okla.) was used for all statistical analyses. The results are presented as medians and twenty-fifth to seventy-fifth percentile ranges. The Friedman analysis of variance test was used for analyses of time series within each group. When significant differences were obtained, these were further evaluated by the Wilcoxon matched pairs test for comparison between two samples within the series. The Mann-Whitney $U$ test was used for intergroup comparisons. Prevalences were evaluated by Fisher's exact test and correlation analyses were done with the Spearman rank order correlation. A $p$ value of less than 0.05 was considered to be statistically significant.

\section{Results}

There were no significant intergroup differences in clinical parameters or blood loss (Table I). The postoperative course was uneventful for all patients except one who needed prolonged ventilatory support because of respiratory insufficiency. 

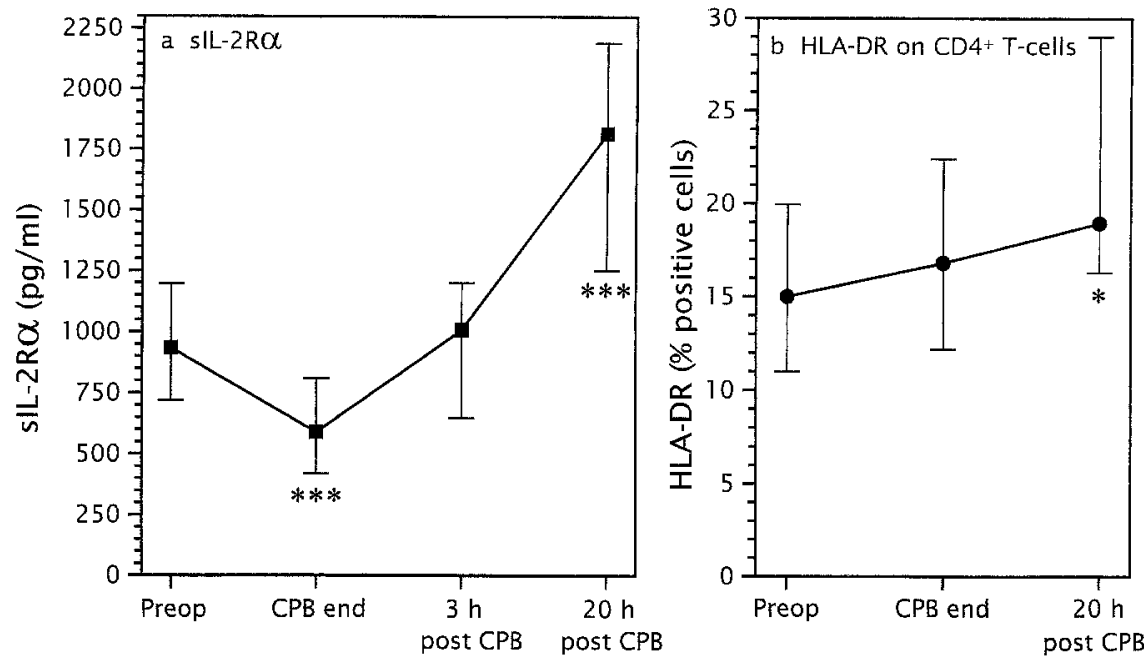

Fig. 4. a, Soluble IL-2R $\alpha(s I L-2 R \alpha)$ in plasma and $\mathbf{b}$, human leukocyte antigen-DR (HLA-DR) on CD4 ${ }^{+}$ $\mathrm{T}$ cells before and after CPB. At the end of CPB, soluble IL-2R $\alpha$ levels decreased as a result of hemodilution. After the termination of $\mathrm{CPB}$, the levels increased and elevated levels of the cytokine were observed 20 hours later. At this time, an elevation was also observed in the human leukocyte antigen-DR levels on $\mathrm{CD} 4^{+} \mathrm{T}$ cells. Data shown as median values and $25 \%$ to $75 \%$ ranges. ${ }^{*} p=0.03$; ${ }^{* * *} p<0.001$ in comparison with preoperative levels.

For all measured parameters, statistical analyses were done for both groups with either heparincoated CPB or standard surfaces. However, between the two groups no significant difference was observed for any of the measured parameters. Therefore the data are presented as one set.

Cell counts. A modest decrease in the total leukocyte count $(p=0.03)$, neutrophil count (not significant), and monocyte count $(p<0.0001)$ was observed during the first hour of CPB. During the later phase of $\mathrm{CPB}$, an increase in the total leukocyte count was observed, which was attributed to an increase in the neutrophil count, whereas the monocyte and lymphocyte counts decreased. A further increase in the neutrophil count was observed 20 hours after the end of CPB. At this time, the monocyte count was also elevated. The relation between lymphocytes and monocytes decreased from more than $3: 1$ before operation to less than 1:1 on the first postoperative morning.

Coagulation activity. The TAT levels gradually increased during $\mathrm{CPB}$ with an almost 20 -fold increase at the end of CPB (Fig. 1). Three hours later, the TAT concentrations had further increased. By the first postoperative morning the levels had decreased, but compared with baseline levels a fivefold enhancement was still observed $(p<0.0001)$.
Before operation, $2.2 \%(0 \%$ to $5.2 \%)$ of freshly isolated monocytes expressed TF (Fig. 2, a). At the end of CPB there was no increase in the TF levels (2.4\% [0\% to $12.8 \%])$. However, at this time, a monocyte TF expression of $10 \%$ or more was found in 5 of the 20 patients, as compared with only 2 patients before the operation. A significant $(p=0.02)$ increase in the TF levels was recorded 20 hours after CPB with $4.6 \%$ (2.2\% to $12.0 \%$ ) of the monocytes expressing TF and with more than $10 \%$ of the monocytes positive for TF in five of the patients. No patient had $0 \%$ TFexpressing monocytes the day after the operation, as compared with six patients before operation and five at the end of CPB.

To evaluate the capacity of the monocytes to express TF on their surface, we incubated the mononuclear cells with $0.1 \mu \mathrm{g} / \mathrm{ml}$ of lipopolysaccharide for 4 hours. The TF-inducing capacity, as measured by the number of TF receptors per cell (MFI), by lipopolysaccharide stimulation, was decreased at the end of CPB $(p=0.003)$ (Fig. 2, b). However, the number of TF-positive cells was not significantly changed compared with preoperative levels. In contrast, the sensitivity to lipopolysaccharide stimulation was significantly enhanced 20 hours after the end of CPB with an increase in both the MFI and the number of TF-positive monocytes $(p=0.001)$. 

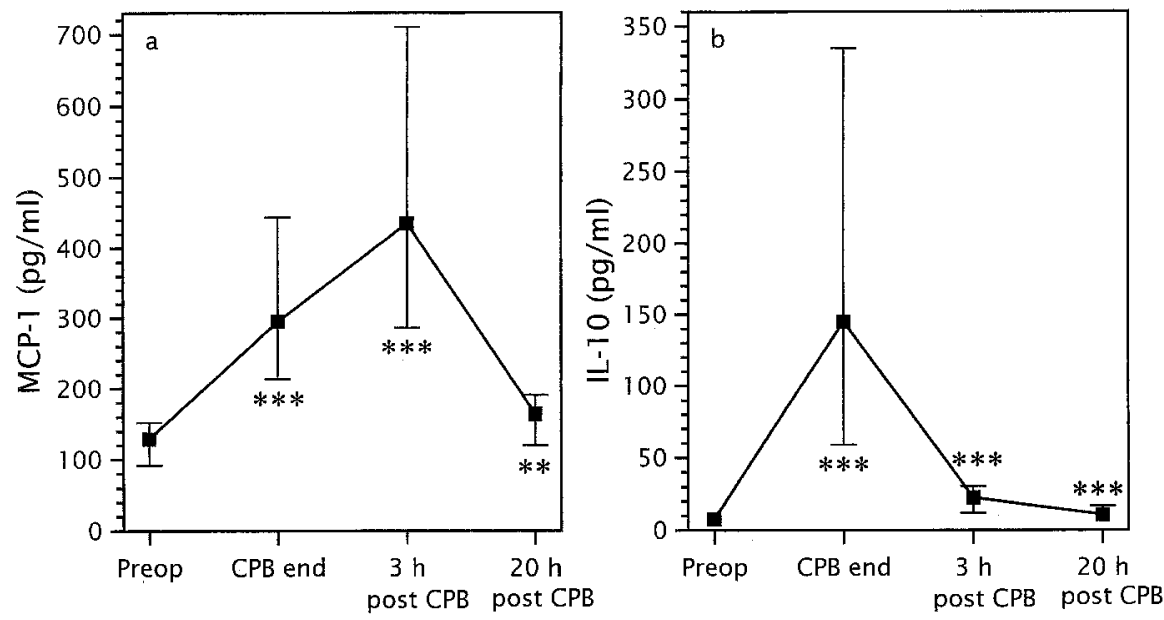

Fig. 5. Generation of (a) MCP-1 and (b) IL-10 before and after CPB. The MCP-1 levels increased during heart operation with $\mathrm{CPB}$, reaching maximum levels 3 hours after termination of $\mathrm{CPB}$. The levels declined the day after the operation, but were still elevated. The IL-10 levels increased extensively during CPB, reaching peak levels at the end of CPB. The IL-10 levels then rapidly declined, although elevated levels were still noticed 20 hours after the end of CPB. Note the large differences between patients with some having very high levels of MCP-1 or IL-10. Data are presented as median values and $25 \%$ to $75 \%$ ranges. $* * p=0.003 ; * * * p<0.001$ in comparison with preoperative levels.

CD11b levels on monocytes and granulocytes. To evaluate the possible cause of the enhanced monocyte TF levels, the expression of the adhesion molecule $\mathrm{CD} 11 \mathrm{~b}$ on the monocytes and the granulocytes was analyzed by flow cytometry. A prominent increase $(p=0.0003)$ in both monocyte and granulocyte cell surface expression of CD11b was recorded at the end of CPB (Fig. 3). The CD11b expression on the monocytes remained unchanged until the first postoperative morning. The expression of $\mathrm{CD} 11 \mathrm{~b}$ on the granulocytes peaked at the end of $\mathrm{CPB}$ and, compared with preoperative values, the expression was still elevated 20 hours after CPB $(p=0.04)$.

Markers of lymphocyte activation. Lymphocytes are known to enhance the expression of TF on monocytes, ${ }^{15}$ so with the purpose of investigating the activation of the lymphocytes, soluble IL-2R $\alpha$ levels were measured. The plasma levels of this receptor decreased significantly $(p<0.0001)$ during CPB (Fig. 4, a). However, this reduction was caused by hemodilution (data not shown). At the end of the investigation period, on the first postoperative morning, soluble IL-2R $\alpha$ levels exhibited an almost twofold increase compared with preoperative levels $(p<0.0001)$, indicating lymphocyte activation.

$\mathrm{T}$ helper/inducer cells are the most essential lymphocytes involved in the generation of monocyte
$\mathrm{TF}^{22}$ Soluble IL-2R $\alpha$ is secreted by all types of lymphocytes. Therefore the expression of human leukocyte antigen-DR on the surface of $\mathrm{CD}^{+} \mathrm{T}$ helper/inducer cells was also analyzed. The levels of this surface bound molecule did not change during CPB (Fig. 4, b). However, a similar pattern of expression of human leukocyte antigen-DR on $\mathrm{CD} 4^{+} \mathrm{T}$ helper/inducer cells and release of soluble IL- $2 \mathrm{R} \alpha$ was recorded with increased levels the first postoperative morning $(p=0.02)$.

Levels of MCP-1 and IL-10. The chemokine MCP-1 is released from a variety of cells, including activated monocytes. MCP-1 is a main activator of monocytes and because we have previously shown that it is also an efficient inducer of TF in human monocytes, ${ }^{14}$ the plasma levels of this chemokine were measured. The levels of MCP-1 increased significantly $(p<0.0001)$ during and shortly after CPB with peak values occurring 3 hours after CPB (Fig. 5, a). At this time, the levels had increased more than threefold compared with values before operation. The levels were still elevated 20 hours after the discontinuation of CPB $(p=0.003)$.

At the end of CPB, the monocytes were less sensitive to endotoxin stimulation. These results might be explained by priming of the cells by yet unknown factors during the operative procedure. To test this hypothesis, the plasma levels of IL-10 were 
Table II. Comparison of levels of coagulation markers, adhesion molecules on leukocytes, and cytokines in patients who underwent $C P B$ with uncoated (group C) or heparin-coated (group HC) circuits

\begin{tabular}{|c|c|c|c|c|c|c|}
\hline & Group & Preop. & $60 \mathrm{Min} C P B$ & $C P B$ end & $3 \mathrm{Hr}$ after $C P B$ & $20 \mathrm{Hr}$ after $\mathrm{CPB}$ \\
\hline \multirow[t]{2}{*}{ TAT $(\mu \mathrm{g} / \mathrm{L})$} & $\mathrm{C}$ & $3.3(2.8-6.8)$ & $23(15-25)$ & $58(40-88)$ & $206(86-382)$ & $15(10-21)$ \\
\hline & $\mathrm{HC}$ & $3.3(2.6-3.6)$ & $23(10-25)$ & $64(33-95)$ & $201(60-402)$ & $18(11-20)$ \\
\hline \multirow{2}{*}{$\begin{array}{l}\text { TF on fresh monocytes } \\
\text { (\% positive cells) }\end{array}$} & $\mathrm{C}$ & $0.45(0.0-4.6)$ & & $2.4(0.0-10)$ & & $4.3(2.0-9.4)$ \\
\hline & $\mathrm{HC}$ & $2.5(0.0-4.6)$ & & $2.0(0.0-4.1)$ & & $4.8(1.7-9.6)$ \\
\hline \multirow{2}{*}{$\begin{array}{l}\text { TF after } 4 \text { hr of LPS } \\
\text { stimulation (MFI) }\end{array}$} & $\mathrm{C}$ & $17(14-19)$ & & $12(7.0-13)$ & & $20(15-27)$ \\
\hline & $\mathrm{HC}$ & $16(7-19)$ & & $11(4.4-9.5)$ & & $20(13-23)$ \\
\hline \multirow{2}{*}{$\begin{array}{l}\text { CD11b on monocytes } \\
\text { (MFI) }\end{array}$} & $\mathrm{C}$ & $5.4(4.3-7.4)$ & & $9.8(8.0-33)$ & & $13(5.0-18)$ \\
\hline & $\mathrm{HC}$ & $6.8(4.3-7.6)$ & & $12(12-20)$ & & $16(10-19)$ \\
\hline \multirow{2}{*}{$\begin{array}{l}\text { CD11b on granulocytes } \\
\text { (MFI) }\end{array}$} & $\mathrm{C}$ & $4.3(4.0-11)$ & & $12(8.4-17)$ & & $9.1(2.5-12)$ \\
\hline & $\mathrm{HC}$ & $5.2(3.9-6.7)$ & & $13(8.9-15)$ & & $7.6(6.0-10)$ \\
\hline \multirow[t]{2}{*}{ Soluble IL-2R $\alpha(\mathrm{pg} / \mathrm{ml})$} & $\mathrm{C}$ & $850(650-1200)$ & & $600(420-750)$ & $980(650-1100)$ & $1600(1200-2100)$ \\
\hline & $\mathrm{HC}$ & $1000(720-1200)$ & & $580(420-840)$ & $1000(650-1300)$ & $1900(1500-2500)$ \\
\hline \multirow{2}{*}{$\begin{array}{l}\text { HLA-DR on } \mathrm{CD}^{+}{ }^{+} \mathrm{T} \text { cells } \\
\text { (\% positive cells })\end{array}$} & $\mathrm{C}$ & $15(11-22)$ & & $17(13-23)$ & & $18(13-22)$ \\
\hline & $\mathrm{HC}$ & $16(9.8-20)$ & & $17(12-27)$ & & $21(14-36)$ \\
\hline \multirow[t]{2}{*}{$\mathrm{MCP}-1(\mathrm{pg} / \mathrm{ml})$} & $\mathrm{C}$ & $130(92-140)$ & & $270(210-300)$ & $370(290-660)$ & $170(98-190)$ \\
\hline & $\mathrm{HC}$ & $130(92-170)$ & & $310(250-520)$ & $440(280-660)$ & $160(120-180)$ \\
\hline \multirow[t]{2}{*}{$\mathrm{IL}-10(\mathrm{pg} / \mathrm{ml})$} & $\mathrm{C}$ & $7.8(7.8-7.8)$ & & $125(59-320)$ & $22(14-30)$ & $15(7.8-18)$ \\
\hline & $\mathrm{HC}$ & $7.8(7.8-7.8)$ & & $165(54-360)$ & $23(7.8-32)$ & $7.8(7.8-12)$ \\
\hline \multirow[t]{2}{*}{ EVF } & $\mathrm{C}$ & $35(33-37)$ & $23(21-26)$ & $22(19-23.5)$ & $28.5(27.5-29.5)$ & $29(27-30.5)$ \\
\hline & $\mathrm{HC}$ & $32.5(29.5-36.5)$ & $23.5(19.5-25.0)$ & $21.5(21.0-24.0)$ & $29(26-30)$ & $29(27-30)$ \\
\hline
\end{tabular}

No significant differences existed between the two groups. The data are presented as medians and $25 \%$ to $75 \%$ percentiles (in parentheses). LPS, Lipopolysaccharide; $H L A-D R$, human leukocyte antigen-DR; $E V F$, erythrocyte volume fraction.

measured. Before CPB, IL-10 levels were less than the lower detection limit of the assay in all patients $(<7.8 \mathrm{pg} / \mathrm{ml})$. The levels increased more than 20 times during CPB followed by a rapid decrease after CPB termination (Fig. 5, $b$ ). On the first postoperative day, the IL-10 levels were still slightly elevated $(p=0.0003)$ with levels greater than the lower detection limit of the assay in $15(58 \%)$ of the 26 patients.

Correlations. The decrease in TF-inducing capacity by lipopolysaccharide at the end of $\mathrm{CPB}$ compared with before operation was significantly correlated with the IL-10 levels at the end of CPB: $R=0.48, p=0.04$. There was no other correlation between TF expression and levels of cytokines or adhesion molecules.

Effect of the heparin-coated device. No significant difference was observed between the two groups for any of the measured parameters (Table II).

\section{Discussion}

The data in this report do not support the hypothesis that TF expression on circulating monocytes is the main cause of the enhanced coagulation activation seen at the end of CPB. There was no statistically significant elevation of monocyte surface expression of TF at this time. Furthermore, the monocytes generated less TF when stimulated with endotoxin in vitro as compared with preoperative TF generation, which probably is a reflection of in vivo priming of the monocytes by yet unknown factors. However, as indicated in this study, IL-10 is likely to be one of these candidates. IL-10 is a powerful monocyte deactivating factor with the ability to inhibit cytokine release. This cytokine is also a potent inhibitor of lipopolysaccharide- and, as we recently have demonstrated, MCP-1-induced TF expression in human monocytes. ${ }^{18}$ Our data indicate that an early release of IL-10 could be of great importance in regulating the monocyte TF expression in vivo.

Although we could not detect any increased TF expression at the end of CPB on monocytes circulating in the blood, it was recently shown by two other groups that TF expression is increased in monocytes adherent to the surface of the CPB circuit, which indicates an important role of the monocytes in inducing thrombin formation. ${ }^{23,24} \mathrm{In}$ accordance with these observations, our results could reflect that the most active and functional monocytes were adherent to the surface of the CPB circuit. Moreover, Chung and colleagues ${ }^{23}$ reported that monocytes in the pericardial blood have significantly increased TF expression. Thus monocytes trapped in the area of operation, in the lungs, in the 
myocardium, or in all these places may also express TF. Another possible source of coagulation activation is TF expressed in the subendothelium and in atherosclerotic plaques, which can be exposed to the blood in the damaged tissue of the area of operation. $^{25,26}$

The coagulation activation could also depend on contact activation through the foreign surfaces of the CPB equipment. ${ }^{5,6}$ Coating of the surfaces of the CPB circuit with heparin is an attempt to increase the biocompatibility of these surfaces. ${ }^{9}$ In this study we used a heparin-coated CPB circuit (Duraflo II), including a heparin-coated cardiotomy reservoir. The thrombin generation was not decreased by the use of such a device, which is in agreement with findings of three previous studies that used another heparin-coating principle (Carmeda Bio-Active Surface). ${ }^{2,10,11}$ Thus the circuit may still be thrombogenic despite the use of heparin-coated internal surfaces. Alternatively, the main source of activation of the coagulation cascade may be provided by some mechanism other than the surface. $^{23}$

The retransfusion of blood from the pericardial cavity by use of a cardiotomy reservoir is highly important in inducing thrombin generation. ${ }^{23,27,28}$ We have observed that operation with use of a cardiotomy reservoir induces higher TAT levels compared with operation with use of a cell salvage device (manuscript in preparation). Monocyte TF expression and thrombin generation are high in the pericardial blood. ${ }^{23}$ Similarly, the extremely high level of TAT 3 hours after the termination of $\mathrm{CPB}$, which is in contrast with findings of our previous study, ${ }^{2}$ is probably a result of the retransfusion of shed mediastinal blood.

In this study we show for the first time that the levels of TF on circulating monocytes are elevated 20 hours after CPB arrest. This upregulation of TF may, at least partly, explain the remaining thrombin generation. Additionally, we also found that the monocytes are hyperactive in generating TF expression on activation with endotoxin. It is highly possible that the cells were primed in vivo by signaling agonists, such as cytokines.

One of these cytokine candidates is MCP-1, a potent inducer of TF expression on monocytes. ${ }^{14}$ We show that MCP-1 is released during heart operations with CPB and reaches very high levels 3 hours after CPB. Furthermore, the morning after operation the levels are still significantly increased. Thus it is possible that MCP-1 is involved in the monocyte TF generation during and after CPB. It is questionable, however, whether this cytokine is the main cause of the TF generation. Although other authors have shown no or only modest increases of $\mathrm{IL}-1 \beta$ and tumor necrosis factor during CPB, these cytokines are additional candidates. ${ }^{29,30}$

The enhanced activity of $\mathrm{T}$ helper/inducer cells, granulocytes, or monocytes, or all of these, on the first postoperative morning can also explain the enhanced TF generation because these cells are known to have stimulatory effects on the generation of TF in the monocytes. ${ }^{15,22}$ However, no statistically significant correlation between the markers of cell activation and TF expression was observed. This result might be because of the relatively small number of patients in the study. Lymphocytes are required to optimize the in vitro induction of monocyte $\mathrm{TF}$ expression and the optimal lymphocyte/ monocyte ratio is $4: 1$ or more. ${ }^{15}$ Despite a low lymphocyte/monocyte ratio (1:1) 20 hours after CPB, we observed an increased sensitivity toward endotoxin, which indicated that the cells were primed by strong TF-inducing factors.

In conclusion, at the end of CPB the generation of thrombin occurred without a simultaneous elevation of TF expression on circulating monocytes. In contrast, TF expression on circulating monocytes was enhanced 20 hours after CPB. This TF expression may, at least partly, explain the enhanced coagulation activation. The interaction between activated lymphocytes, granulocytes, and monocytes or agonists released late in the bypass period may result in stimulation of the monocytes to express TF. However, the regulatory mechanism and the clinical relevance of this monocyte $\mathrm{TF}$ expression are today not fully elucidated.

We thank Eva Thörnö, Elisabeth Ahlvin, Gunilla Liss, and Petter Halldén for skillful technical assistance.

\section{REFERENCES}

1. Tanaka K, Takao M, Yada I, Yuasa H, Kusagawa M, Deguchi $\mathrm{K}$. Alterations in coagulation and fibrinolysis associated with cardiopulmonary bypass during open heart surgery. J Cardiothorac Anesth 1989;3:181-8.

2. Ennofsson M, Thelin S, Siegbahn A. Thrombin generation during cardiopulmonary bypass using heparin-coated or standard circuits. Scand J Thorac Cardiovasc Surg 1995;29:15765.

3. Wachtfogel YT, Kucich U, Greenplate J, et al. Human neutrophil degranulation during extracorporeal circulation. Blood 1987;69:324-30.

4. Kappelmayer J, Bernabei A, Gikakis N, Edmunds LH Jr, Colman RW. Upregulation of Mac-1 surface expression on 
neutrophils during simulated extracorporeal circulation. J Lab Clin Med 1993;121:118-26.

5. Colman RW. Hemostatic complications of cardiopulmonary bypass. Am J Hematol 1995;48:267-72.

6. Irvine L, Sundaram S, Courtney JM, Taggart DP, Wheatley DJ, Lowe GDO. Monitoring of factor XII activity and granulocyte elastase release during cardiopulmonary bypass. ASAIO Trans 1991;37:569-71.

7. Boisclair MD, Lane DA, Philippou $\mathrm{H}$, et al. Mechanisms of thrombin generation during surgery and cardiopulmonary bypass. Blood 1993;82:3350-7.

8. Burman JF, Chung HI, Lane DA, Philippou H, Adami A, Lincoln JCR. Role of factor XII in thrombin generation and fibrinolysis during cardiopulmonary bypass. Lancet 1994;344: 1192-3.

9. Larm O, Larsson R, Olsson P. A new non-thrombogenic surface prepared by selective covalent binding of heparin via a modified reducing terminal residue. Biomat Med Dev Artif Organs 1983;11:161-73.

10. Gorman RC, Ziats NP, Rao AK, et al. Surface-bound heparin fails to reduce thrombin formation during clinical cardiopulmonary bypass. J Thorac Cardiovasc Surg 1996;111:1-11.

11. Wagner WR, Johnson PC, Thompson KA, Marrone GC. Heparin-coated cardiopulmonary bypass circuits: hemostatic alterations and postoperative blood loss. Ann Thorac Surg 1994;58:734-41.

12. Gu YJ, van Oeveren W, van der Kamp KWHJ, Akkerman C, Boonstra PW, Wildevuur CRH. Heparin-coating of extracorporeal circuits reduces thrombin formation in patients undergoing cardiopulmonary bypass. Perfusion 1991;6:221-5.

13. Camerer E, Kolst $ø$ A-B, Prydz H. Cell biology of tissue factor, the principal initiator of blood coagulation. Thromb Res 1996;81:1-41.

14. Ernofsson M, Siegbahn A. Platelet-derived growth factor-BB and monocyte chemotactic protein- 1 induce human peripheral blood monocytes to express tissue factor. Thromb Res 1996;83:307-20.

15. Levy GA, Edgington TS. Lymphocyte cooperation is required for amplification of macrophage procoagulant activity. J Exp Med 1980;151:1232-44.

16. Østerud B. Cellular interactions in tissue factor expression by blood monocytes. Blood Coagul Fibrinolysis 1995;6(suppl 1): $\$ 20-5$

17. Fan S-T, Edgington TS. Coupling of the adhesive receptor $\mathrm{CD} 11 \mathrm{~b} / \mathrm{CD} 18$ to functional enhancement of effector macrophage tissue factor response. J Clin Invest 1991;87:50-7.

18. Ernofsson M, Tenno T, Siegbahn A. Inhibition of tissue factor expression in human peripheral blood monocytes exposed to cytokines. Br J Haematol 1996;95:249-57.
19. Kappelmayer J, Bernabei A, Edmunds LH Jr, Edgington TS, Colman RW. Tissue factor is expressed on monocytes during simulated extracorporeal circulation. Circ Res 1993;72:107581.

20. Friberger P, Knös M, Mellstam L. A quantitative endotoxin assay utilizing $\mathrm{LAL}$ and a chromogenic substrate. In: Watson SW, Levin J, Novitsky TJ, editors. Progress in clinical and biological research: endotoxins and their detection with the Limulus amebocyte lysate test. New York: Alan R. Liss, 1982:195-206.

21. Hamblin A, Taylor M, Bernhagen $\mathbf{J}$, et al. A method of preparing blood leukocytes for flow cytometry which prevents upregulation of leukocyte integrins. J Immunol Methods 1992;146:219-28.

22. Gregory SA, Edgington TS. Tissue factor induction in human monocytes: two distinct mechanisms displayed by different alloantigen-responsive T cell clones. J Clin Invest 1985;76: 2440-5.

23. Chung JH, Gikakis N, Rao AK, Drake TA, Colman RW, Edmunds LH Jr. Pericardial blood activates the extrinsic coagulation pathway during clinical cardiopulmonary bypass. Circulation 1996;93:2014-8.

24. Barstad RM, Øvrum E, Ringdal M-AL, et al. Induction of monocyte tissue factor procoagulant activity during coronary artery bypass surgery is reduced with heparin-coated extracorporeal circuit. Br J Haematol 1996;94:517-25.

25. Weiss HJ, Turitto VT, Baumgartner HR, Nemerson Y, Hoffman T. Evidence for the presence of tissue factor activity on subendothelium. Blood 1989;73:968-75.

26. Wilcox JN, Smith KM, Schwartz SM, Gordon D. Localization of tissue factor in normal vessel wall and in the atherosclerotic plaque. Proc Nati Acad Sci U S A 1989;86: $2839-43$

27. Tabuchi N, de Haan J, Boonstra PW, van Oeveren W. Activation of fibrinolysis in the pericardial cavity during cardiopulmonary bypass. J Thorac Cardiovasc Surg 1993;106: 828-33.

28. de Haan J, Boonstra PW, Monnink SHJ, Ebels T, van Oeveren W. Retransfusion of suctioned blood during cardiopulmonary bypass impairs hemostasis. Ann Thorac Surg 1995;59:901-7.

29. Frering B, Philip I, Dehoux M, Rolland C, Langlois JM, Desmonts JM. Circulating cytokines in patients undergoing normothermic cardiopulmonary bypass. J Thorac Cardiovasc Surg 1994;108:636-41.

30. Deng MC, Weidner M, Erren M, Möllhoff T, Assmann G, Scheld HH. Arterial and venous cytokine response to cardiopulmonary bypass for low risk $\mathrm{CABG}$ and relation to hemodynamics. Eur J Cardiothorac Surg 1995;9:22-9. 